A C G

Rec. Nat. Prod. 16:1 (2022) 27-33

records of natural

products

publications

\title{
Diterpenoids from the Roots of Clerodendrum bungei
}

\section{Dong-Xiang Wu $\oplus^{1}$, Jin-Hai Yu $\oplus^{1}$, Xiu-Qing Song $\oplus^{1}$, Yu-Zhen Ma $\odot^{2}$, Peipei Shan $\oplus^{3^{*}}$ and Hua Zhang}

\author{
${ }^{I}$ School of Biological Science and Technology, University of Jinan, Jinan 250022, China \\ ${ }^{2}$ Department of Food and Drugs, Shandong Institute of Commerce \& Technology, Jinan 250103, \\ China \\ ${ }^{3}$ Institute of Translational Medicine, the Affiliated Hospital of Qingdao University, College of \\ Medicine, Qingdao University, Qingdao 266021, China \\ (Received March 05, 2021; Revised April 01, 2021; Accepted April 22, 2021)
}

\begin{abstract}
Two new rearranged abietane diterpenoids (1 and 2), together with eleven previously described analogues (3-13), were obtained from the ethanolic extract of a traditional ethnological herb, Clerodendrum bungei. The structures with absolute configurations of the new compounds were unambiguously characterized via spectroscopic methods, and that of the formerly reported crolerodendrum B (3) was corrected in the present work. Biological assessment of these isolates revealed that diterpenoids 2, 4, 6 and 12 showed significant inhibition against $\alpha$-glucosidase enzyme with $\mathrm{IC}_{50}$ values in the range of $17.0-25.7 \mu \mathrm{M}$.
\end{abstract}

Keywords: Clerodendrum bungei; abietane diterpenoid; $\alpha$-glucosidase. () 2021 ACG Publications. All rights reserved.

\section{Introduction}

Clerodendrum bungei Steud., a medicinal species from the biggest genus Clerodendrum of family Verbenaceae, is a shrub of one to two meters tall with unpleasant odor [1], and it is widely distributed in most areas of China except in the northeast. In addition to serving as an ornamental plant due to its beautiful flowers, roots, stems and leaves of $C$. bungei have also been used as herbal medicine in China to relieve swelling, alleviate pain, remove external heat, and so on. Particularly, the roots of $C$. bunge $i$ are a well-known ethnodrug called "Binliang" of the "Dai" people living in Yunnan Province [2]. Besides the rich volatile oil constituents [3] revealed by GC-MS technique, previous phytochemical studies on $C$. bungei also showed the presence of triterpenoids [4] and steroids [5]. Moreover, the most attracting bioactive ingredients from this herb are abietane diterpenoids [6-8] that have exerted interesting anti-complement effect [9], as well as angiotensin converting enzyme (ACE) [10] and $\alpha$-glucosidase [11] inhibitory activities.

As part of our efforts to explore new bioactive small molecules from "Dai" medicinal plants, the chemical constituents in the roots of $C$. bungei have been systematically investigated in the present work. As a result, two new rearranged abietane diterpenoids (1 and $\mathbf{2})$, as well as 11 known ones (Figure 1), were isolated and characterized. Our bioassay revealed remarkable $\alpha$-glucosidase

${ }^{\text {*} C o r r e s p o n d i n g ~ a u t h o r s: ~ E-m a i l s: ~ b i o ~ z h a n g h @ u j n . e d u . c n ~ ; ~ s h a n p e i p e i @ q d u . e d u . c n ~}$

The article was published by ACG Publications

http://www.acgpubs.org/journal/records-of-natural-products January-February 2022 EISSN:1307-6167

DOI: http://doi.org/10.25135/rnp.245.21.03.2000

Available online May 05, 2021 
inhibitory activity for selective diterpenoids. This paper deals with the separation, structure determination and biological evaluation of these compounds.

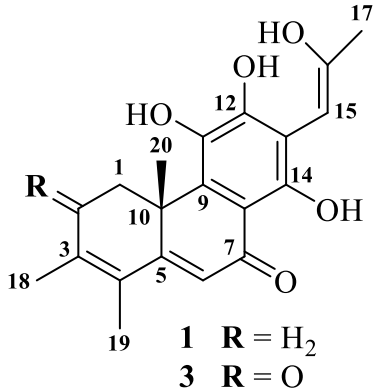<smiles>COc1c(O)c(C[C@H](C)O)c(O)c2c1[C@]1(C)CCC(C)=C(C)C1=CC2=O</smiles><smiles>[R]C1=C(C)C(C)=C2C=C(O)c3c(c(O)c4oc(C)c(C)c4c3O)[C@@]2(C)C1</smiles>

$4 \mathbf{R}=\mathrm{H}_{2}$

$5 \mathbf{R}=\mathrm{O}$

$6 \mathbf{R}=\mathrm{H}_{2}, \triangle^{15}$

$7 \mathbf{R}=\mathrm{O}, \triangle^{15}$

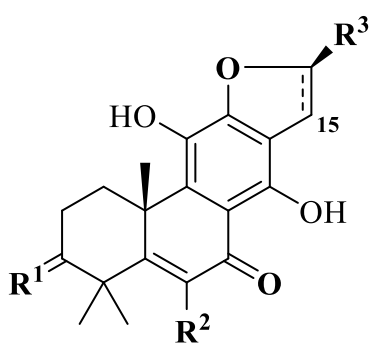

$\begin{array}{clll} & \mathbf{R}^{\mathbf{1}} & \mathbf{R}^{\mathbf{2}} & \mathbf{R}^{\mathbf{3}} \\ \mathbf{8} & \mathrm{O} & \mathrm{OMe} & \mathrm{Me}, \triangle^{15} \\ \mathbf{9} & \mathrm{H}_{2} & \mathrm{H} & \mathrm{CH}_{2} \mathrm{OH} \\ \mathbf{1 0} & \mathrm{H}_{2} & \mathrm{OH} & \mathrm{CH}_{2} \mathrm{OH}, \triangle^{15} \\ \mathbf{1 1} & \mathrm{H}_{2} & \mathrm{OMe} & \mathrm{CH}_{2} \mathrm{OH} \\ \mathbf{1 2} & \mathrm{H}_{2} & \mathrm{OMe} & \mathrm{CH}_{2} \mathrm{OH}, \triangle^{15}\end{array}$<smiles>CC(C)c1cc2c(cc1O)[C@]1(C)CCCC(C)(C)[C@H]1CC2=O</smiles>

Figure 1. Structures of diterpenoids from $C$. bungei

\section{Materials and Methods}

\subsection{General}

Optical rotations were measured on a Rudolph VI polarimeter (Rudolph Research Analytical, Hackettstown, USA) with a $10 \mathrm{~cm}$ length cell. ECD spectra were recorded on a Chirascan photospectrometer (Applied Photophysics Ltd., Leatherhead, UK) with a $0.1 \mathrm{~cm}$ pathway cell. NMR experiments were carried out on a Bruker Avance DRX600 spectrometer (Bruker BioSpin AG, Fallanden, Switzerland) and referenced to residual solvent peaks $\left(\mathrm{CDCl}_{3}: \delta_{\mathrm{H}} 7.26, \delta_{\mathrm{C}} 77.16 ; \mathrm{CD}_{3} \mathrm{OD}\right.$ : $\left.\delta_{\mathrm{H}} 3.31, \delta_{\mathrm{C}} 49.00\right)$. HR-ESIMS spectra were recorded on an Agilent 6545 Q-TOF mass spectrometer (Agilent Technologies Inc., Waldbronn, Germany). ESIMS analyses were conducted on an Agilent 6460 Triple Quad LC-MS instrument (Agilent Technologies Inc., Waldbronn, Germany). All HPLC separations were performed using an Agilent 1260 series LC instrument (Agilent Technologies Inc., Waldbronn, Germany) coupled with an YMC ODS-pack column $(10 \times 250 \mathrm{~mm}$, Agilent Technologies Inc., Santa Clara, USA). Column chromatography (CC) was carried out on reversed phase $\mathrm{C}_{18}$ (RP-18) silica gel (Merck KGaA, Darmstadt, Germany), Sephadex LH-20 (GE Healthcare Bio-Sciences AB, Uppsala, Sweden) and silica gel (300-400 mesh; Qingdao Marine Chemical Co. Ltd., Qingdao, China). All solvents used for CC were of analytical grade (Tianjin Fuyu Fine Chemical Co. Ltd., Tianjin, China) and solvents used for HPLC were of HPLC grade (Oceanpak Alexative Chemical Ltd., Goteborg, Sweden). Pre-coated silica gel $\mathrm{GF}_{254}$ plates (Qingdao Marine Chemical Co. Ltd., Qingdao, China) were used for thin layer chromatography (TLC) analyses. All solvent mixtures used for HPLC and CC analyses and separations were presented as the ratio of volume to volume, unless otherwise specified.

\subsection{Plant Material}

The roots of Clerodendrum bungei Steud. were collected in October 2018 in Jinghong, Yunnan province, China, and were authenticated by Prof. Guo-hua Ye from Shandong College of Traditional Chinese Medicine. A voucher specimen has been deposited at School of Biological Science and Technology, University of Jinan (Accession number: npmc-039). 


\subsection{Extraction and Isolation}

The air-dried powdered roots $(30 \mathrm{~kg})$ of $C$. bungei were extracted with $95 \% \mathrm{EtOH}$ at room temperature for three times (once for a week), and the extracting solvent was removed under reduced pressure to return a dark residue $(1.35 \mathrm{~kg})$. The residue was re-suspended in $1.5 \mathrm{~L}$ water and partitioned successively with EtOAc $(1.5 \mathrm{~L} \times 3)$ and $n$ - BuOH $(2.0 \mathrm{~L} \times 3)$ to afford the EtOAc and $n$ $\mathrm{BuOH}$ soluble extracts, respectively. The EtOAc soluble part $(110 \mathrm{~g})$ was chromatographed over MCI absorption resin, eluted with $\mathrm{MeOH}-\mathrm{H}_{2} \mathrm{O}(30 \%, 50 \%, 80 \%$ and $95 \%)$, to give four fractions (A, B, C and $\mathrm{D})$. Fraction $\mathrm{D}(30 \mathrm{~g})$ was subjected to a silica gel column using petroleum ether (PE)-EtOAc (20:1 to 5:1) as eluent, to acquire 11 subfractions (D1-D11). The subfraction D3 (1.2 g) was applied to Sephadex LH-20 CC $\left(\mathrm{CH}_{2} \mathrm{Cl}_{2}-\mathrm{MeOH}, 1: 1\right)$ to afford three fractions (D3-1-D3-3). Fraction D3-1 (350 $\mathrm{mg})$ was purified by semi-preparative $\mathrm{HPLC}\left(3.0 \mathrm{~mL} / \mathrm{min}, 85 \% \mathrm{MeOH}-\mathrm{H}_{2} \mathrm{O}\right)$ to yield compounds 4 $\left(8.7 \mathrm{mg}, t_{\mathrm{R}}=11.6 \mathrm{~min}\right)$ and $\mathbf{1}\left(2.8 \mathrm{mg}, t_{\mathrm{R}}=12.5 \mathrm{~min}\right)$. Fraction D3-3 $(50 \mathrm{mg})$ was separated by silica gel $\mathrm{CC}\left(\mathrm{CH}_{2} \mathrm{Cl}_{2}-\mathrm{MeOH}, 40: 1\right)$ and then purified by $\mathrm{HPLC}\left(3.0 \mathrm{~mL} / \mathrm{min}, 85 \% \mathrm{MeOH}-\mathrm{H}_{2} \mathrm{O}\right)$ to yield compounds $9\left(0.8 \mathrm{mg}, t_{\mathrm{R}}=13.3 \mathrm{~min}\right)$ and $13\left(1.3 \mathrm{mg}, t_{\mathrm{R}}=16.5 \mathrm{~min}\right)$. Fractions D10 and D11 were combined and fractionated by Sephadex LH-20 CC $\left(\mathrm{CH}_{2} \mathrm{Cl}_{2}-\mathrm{MeOH}, 1: 1\right)$ and HPLC $(3.0 \mathrm{~mL} / \mathrm{min}$, $\left.85 \% \mathrm{MeOH}-\mathrm{H}_{2} \mathrm{O}\right)$ to afford compounds $7\left(1.3 \mathrm{mg}, t_{\mathrm{R}}=5.7 \mathrm{~min}\right), \mathbf{8}\left(0.7 \mathrm{mg}, t_{\mathrm{R}}=11.2 \mathrm{~min}\right)$ and $\mathbf{5}(6.4$ $\left.\mathrm{mg}, t_{\mathrm{R}}=11.8 \mathrm{~min}\right)$. The mother solution of $\mathrm{D} 4(2.6 \mathrm{~g})$, a portion crystallized in methanol, was separated by Sephadex LH-20 CC $\left(\mathrm{CH}_{2} \mathrm{Cl}_{2}-\mathrm{MeOH}, 1: 1\right)$ to produce two subfractions (D4-1 and D4-2). The fraction D4-1 was separated on RP-18 silica gel CC, eluted with $\mathrm{MeOH}-\mathrm{H}_{2} \mathrm{O}$ (70\% to $100 \%$ ), to obtain two subfractions, and the first one was subjected to silica gel CC (PE-EtOAc, 1:1) and then purified by HPLC $\left(3.0 \mathrm{~mL} / \mathrm{min}, 80 \% \mathrm{MeOH}-\mathrm{H}_{2} \mathrm{O}\right)$ to yield compound $2\left(10.3 \mathrm{mg}, t_{\mathrm{R}}=10.1 \mathrm{~min}\right)$. The fraction D4-2 was separated by HPLC $\left(3.0 \mathrm{~mL} / \mathrm{min}, 87 \% \mathrm{MeOH}-\mathrm{H}_{2} \mathrm{O}\right)$ to yield compounds 10 (1.7 $\left.\mathrm{mg}, t_{\mathrm{R}}=5.1 \mathrm{~min}\right), 12\left(1.1 \mathrm{mg}, t_{\mathrm{R}}=11.0 \mathrm{~min}\right)$ and $11\left(11.8 \mathrm{mg}, t_{\mathrm{R}}=11.7 \mathrm{~min}\right)$. The fraction $\mathrm{C}(23 \mathrm{~g})$ was chromatographed using the same procedure as fraction D to produce 11 subfractions $(\mathrm{C} 1-\mathrm{C} 11)$. The fifth fraction C5 (1.2 g) was first fractionated by silica gel CC (PE-EtOAc, 20:1 to 1:1) and then purified by HPLC $\left(3.0 \mathrm{~mL} / \mathrm{min}, 80 \% \mathrm{MeOH}-\mathrm{H}_{2} \mathrm{O}\right)$ to yield compound $3\left(4.1 \mathrm{mg}, t_{\mathrm{R}}=13.0 \mathrm{~min}\right)$. The fraction $\mathrm{C} 8$ was fractionated by $\mathrm{RP}-18 \mathrm{CC}\left(\mathrm{MeOH}-\mathrm{H}_{2} \mathrm{O}, 60 \%\right.$ to $\left.100 \%\right)$ to generate two subfractions, and the second one was purified by HPLC $\left(3.0 \mathrm{~mL} / \mathrm{min}, 75 \% \mathrm{MeOH}-\mathrm{H}_{2} \mathrm{O}\right)$ to yield compound 6 (3.5 $\left.\mathrm{mg}, t_{\mathrm{R}}=10.3 \mathrm{~min}\right)$.

(-)-Crolerodendrum A (1): Orange powder; $[\alpha]_{\mathrm{D}}^{25}-30.1(c 0.56, \mathrm{MeOH}) ; \mathrm{UV} \lambda(\log \varepsilon) 227$ (3.98), 289 (3.68), $332(3.53) \mathrm{nm}$; ECD $(c 0.02, \mathrm{MeOH}) \lambda(\Delta \varepsilon) 347(-3.1), 318(+4.9), 251(+8.0), 228(-8.5), 207$ $(-13.0) ;{ }^{1} \mathrm{H}$ and ${ }^{13} \mathrm{C}$ NMR see Table 1 ; (+)-HR-ESIMS $m / z 325.1431\left[\mathrm{M}+\mathrm{H}-\mathrm{H}_{2} \mathrm{O}\right]^{+}$(calcd for $\left.\mathrm{C}_{20} \mathrm{H}_{21} \mathrm{O}_{4}, 325.1434\right)$.

(-)-Crolerodendrum $C$ (2): Yellow powder; $[\alpha]_{\mathrm{D}}^{25}-102.5(c 0.13, \mathrm{MeOH}) ; \mathrm{UV}(\mathrm{MeOH}) \lambda(\log \varepsilon) 283$ (3.95), 327 (3.84) nm; ECD (c 0.02, MeOH) $\lambda(\Delta \varepsilon) 346$ (-7.5), 317 (+12.2), $251(+7.2), 226(-12.8)$, $210(-12.3) ;{ }^{1} \mathrm{H}$ and ${ }^{13} \mathrm{C}$ NMR see Table 1; HR-ESIMS $\mathrm{m} / z$, 359.1850 $[\mathrm{M}+\mathrm{H}]^{+}$, (calcd for $\mathrm{C}_{21} \mathrm{H}_{27} \mathrm{O}_{5}$, $359.1853)$.

\subsection{Preparation of $(S)$ and (R)-MTPA Esters of compound 2}

To a solution of $2(1.3 \mathrm{mg})$ in pyridine $(500 \mu \mathrm{L})$ was added $(R)-(-)$ - $\alpha$-methoxy- $\alpha$ (trifluoromethyl)phenylacetyl chloride $(10.0 \mu \mathrm{L})$ and dimethylaminopyridine (DMPA, $2.0 \mathrm{mg}$ ). The solution was allowed to stand at room temperature for $6 \mathrm{~h}$. The acquired residue after evaporation of the solvent was applied to semi-preparative HPLC to afford the (S)-MTPA ester 2a $(0.4 \mathrm{mg})$. The $(R)$ MTPA ester $\mathbf{2 b}$ was obtained from $(S)-(+)$ - $\alpha$-methoxy- $\alpha$-(trifluoromethyl)phenylacetyl chloride using the same protocol.

\subsection{ECD Calculations}

The theoretical ECD spectra of compound $\mathbf{1}$ and its enantiomer were acquired by Timedependent Density Functional Theory (TD-DFT) method as we described formerly [12]. 


\section{6. $\alpha$-Glucosidase Inhibitory Assay}

The $\alpha$-glucosidase inhibitory activity of all the compounds were evaluated as depicted in a previous report [12]. A single concentration of $100 \mu \mathrm{M}$ was chosen for the primary screening, and only compounds showing inhibition ratio above $50 \%$ were further submitted for $\mathrm{IC}_{50}$ measurements. Acarbose was used as the positive control $\left(\mathrm{IC}_{50}=236.0 \pm 14.0 \mu \mathrm{M}\right)$.

\section{Results and Discussion}

Compound 1 was assigned the molecular formula of $\mathrm{C} 20 \mathrm{H} 22 \mathrm{O} 5$ based on the HR-ESIMS ion peak at $m / z 325.1431$ (calcd for $\left[\mathrm{M}+\mathrm{H}-\mathrm{H}_{2} \mathrm{O}\right]^{+}, 325.1434$ ). The ${ }^{1} \mathrm{H}$ NMR data (Table 1) for 1 displayed resonances for a remarkably downfield shifted hydroxy proton $\left(\delta_{\mathrm{H}} 14.14\right)$, two olefinic protons $\left(\delta_{\mathrm{H}}\right.$ 6.60 and 6.28$)$, two methylene protons $\left(\delta_{\mathrm{H}} 3.31,2.55,2.24\right.$ and 1.64$)$ and four methyl groups $\left(\delta_{\mathrm{H}} 2.46\right.$, $1.93,1.90$ and 1.54).

Table $1 .{ }^{1} \mathrm{H}$ and ${ }^{13} \mathrm{C}$ NMR data of $\mathbf{1}$ and $\mathbf{2}(\delta$ in ppm, $J$ in $\mathrm{Hz})$

\begin{tabular}{|c|c|c|c|c|c|c|}
\hline \multirow[b]{2}{*}{ No. } & \multicolumn{2}{|r|}{$\mathbf{1}^{\mathrm{a}}$} & \multicolumn{2}{|r|}{$2^{\mathrm{a}}$} & \multicolumn{2}{|r|}{$2^{\mathbf{b}}$} \\
\hline & $\delta_{\mathrm{C}}$ & $\delta_{\mathrm{H}}$ & $\delta_{\mathrm{C}}$ & $\delta_{\mathrm{H}}$ & $\delta_{\mathrm{C}}$ & $\delta_{\mathrm{H}}$ \\
\hline 1 & 29.9 & 3.31, ddd $(13.4,5.8,1.4)$ & 29.3 & 3.23, ddd $(13.3,5.7,1.3)$ & 30.4 & 3.43 ddd $(13.3,5.7,1.4)$ \\
\hline 2 & 30.5 & $\begin{array}{c}1.64, \text { ddd }(13.4,11.9,5.9) \\
2.55, \mathrm{~m} \\
2.24, \mathrm{dd}(19.1,5.8)\end{array}$ & 30.4 & $\begin{array}{c}1.54, \operatorname{ddd}(13.3,11.9,5.9) \\
2.52, \mathrm{~m} \\
2.22, \mathrm{dd}(19.3,5.7)\end{array}$ & 31.2 & $\begin{array}{c}1.48, \mathrm{~m} \\
2.55, \mathrm{~m} \\
2.24, \mathrm{dd}(19.2,5.7)\end{array}$ \\
\hline 3 & 141.0 & & 141.6 & & 143.1 & \\
\hline 4 & 125.5 & & 125.5 & & 126.3 & \\
\hline 5 & 166.1 & & 166.9 & & 168.8 & \\
\hline 6 & 118.7 & 6.28, br s & 118.6 & $6.27, \mathrm{~s}$ & 119.0 & $6.22, \mathrm{~s}$ \\
\hline 7 & 191.5 & & 190.7 & & 192.1 & \\
\hline 8 & 109.6 & & 111.7 & & 112.1 & \\
\hline 9 & 129.8 & & 134.0 & & 136.1 & \\
\hline 10 & 39.7 & & 39.5 & & 40.9 & \\
\hline 11 & 131.4 & & 139.2 & & 141.6 & \\
\hline 12 & 151.7 & & 151.7 & & 154.9 & \\
\hline 13 & 117.2 & & 118.3 & & 119.6 & \\
\hline 14 & 148.7 & & 155.6 & & 156.4 & \\
\hline 15 & 101.7 & $6.60, \mathrm{q}(1.2)$ & 33.4 & $2.91, \mathrm{dd}(13.9,8.2)$ & 34.2 & $2.89, \mathrm{dd}(12.9,5.7)$ \\
\hline & & & & $2.85, \mathrm{dd}(13.9,3.6)$ & & $2.78, \mathrm{dd}(12.9,6.6)$ \\
\hline 16 & 154.9 & & 68.3 & $4.17, \mathrm{~m}$ & 68.1 & $4.14, \mathrm{~m}$ \\
\hline 17 & 14.1 & $2.46, \mathrm{~d}(1.2)$ & 23.9 & $1.29, \mathrm{~d}(6.2)$ & 23.2 & $1.15, \mathrm{~d}(6.2)$ \\
\hline 18 & 15.2 & 1.93, br s & 15.1 & 1.91, br s & 15.1 & 1.91, br s \\
\hline 19 & 20.9 & 1.90, br s & 20.9 & 1.89, br s & 20.7 & 1.94, br s \\
\hline 20 & 22.7 & $1.54, \mathrm{~s}$ & 22.2 & $1.49, \mathrm{~s}$ & 22.3 & $1.52, \mathrm{~s}$ \\
\hline 11-OMe & & & 61.8 & $3.84, \mathrm{~s}$ & 61.3 & $3.80, \mathrm{~s}$ \\
\hline $14-\mathrm{OH}$ & & $14.14, \mathrm{~s}$ & & $13.92, \mathrm{~s}$ & & \\
\hline
\end{tabular}

${ }^{\text {a }}$ Measured in $\mathrm{CDCl}_{3} ;{ }^{\mathrm{b}}$ Measured in $\mathrm{CD}_{3} \mathrm{OD}$.

The ${ }^{13} \mathrm{C}$ NMR data (Table 1) of $\mathbf{1}$ showed 20 signals corresponding to the aforementioned protonbearing carbons, as well as 12 quaternary carbons including a conjugated carbonyl ( $\left.\delta_{\mathrm{C}} 191.5\right)$, a sp ${ }^{3}$ one $\left(\delta_{\mathrm{C}} 39.7\right)$ and 10 aromatic/olefinic carbons $\left(\delta_{\mathrm{C}}\right.$ 166.1-109.6). These NMR data were highly consistent with those of crolerodendrum A, isolated from the roots of Clerodendrum philipinum [13] which was further confirmed by analysis of 2D NMR data (Figures S3-S6, Supporting information) that compound $\mathbf{1}$ had the same planar structure and relative configuration as crolerodendrum $\mathrm{A}$. Interestingly, the specific optical rotation of 1 showed opposite sign to that of crolerodendrum A, indicating an antipodal enantiomer of the latter. Compound $\mathbf{1}$ was thus identified as (-)crolerodendrum A, and its absolute configuration was determined to be $S$ by comparing its experimental ECD curve with the calculated one (Figure 2A). Thus, the absolute configuration of the formerly reported crolerodendrum A was determined for the first time to be $R$. 


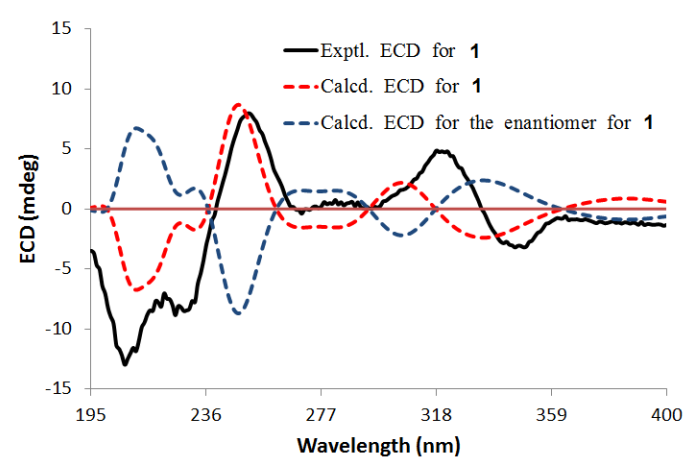

A

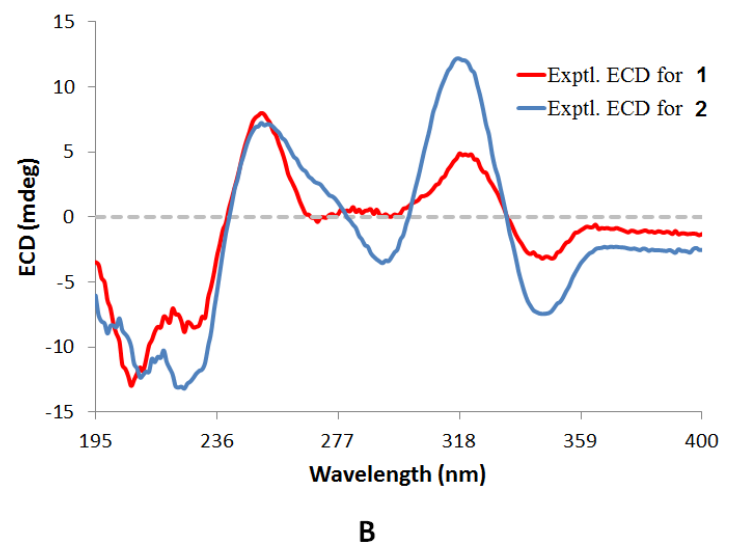

B

Figure 2. Experimental and calculated ECD spectra for $\mathbf{1}$ and $\mathbf{2}$

Compound 2 was assigned the molecular formula of $\mathrm{C}_{21} \mathrm{H}_{26} \mathrm{O}_{5}$ by HR-ESIMS analysis at $\mathrm{m} / \mathrm{z}$ 359.1850 (calcd for $[\mathrm{M}+\mathrm{H}]^{+}, 359.1853$ ). Analysis of the NMR data (Table 1) for $\mathbf{2}$ revealed identical structural features with those of 11-methoxyl-12,14-dihydroxy-13-(2-hydroxypropyl)-3,5,8,11,13abietapentaen-7-one isolated from Clerodendrum kaichianum, the latter being reported with only planar structure [14]. This assignment was further corroborated by detailed examination of 2D NMR data (Figures S11-S14, Supporting information). Interestingly, the specific optical rotation of 2 showed opposite sign to that of the above-mentioned known analogue, indicating an antipodal analogue (enantiomer or diastereoisomer). The absolute configuration at C-16 of $\mathbf{2}$ was assigned to be $S$ by Mosher's method (Fig. 3), while its C-10 absolute configuration was also established to be $S$ on the basis of its consistent ECD curve with that of $\mathbf{1}$ (Fig. 2B). The structure of $\mathbf{2}$ was thus unequivocally elucidated.

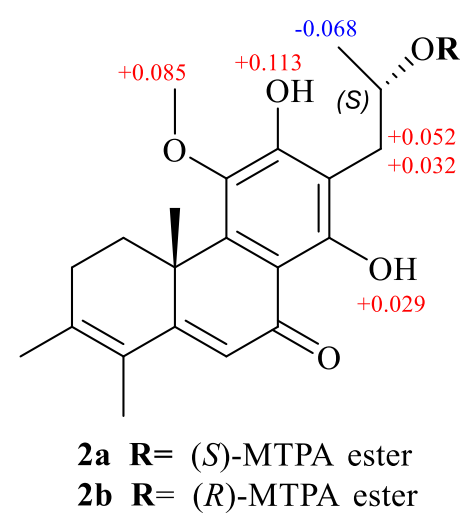

Figure 3. $\Delta \delta\left(\delta_{\mathrm{S}}-\delta_{\mathrm{R}}\right)$ values in ppm for MTPA eaters of 2

Compound $\mathbf{3}$ was identified to be crolerodendrum B, originally reported from Clerodendrum inerme [15], and its $\Delta^{15}$ double bond was initially assigned an E-geometry. However, based on the NOESY correlation of $\mathrm{H}-15$ with $\mathrm{H}_{3}-17$ (Figure S26, Supporting information), $\Delta^{15}$ in $\mathbf{3}$ should be reassigned to be Z-configured. Moreover, the ${ }^{13} \mathrm{C}$ NMR data for both $(E)-\Delta^{15}$ and $(Z)-\Delta^{15}$ isomers of compound 3 were theoretically calculated, and the $(Z)$-isomer showed a much better linear correlation coefficient $\left(R^{2}=0.9949\right)$ than that $\left(R^{2}=0.9891\right)$ of the $(E)$-isomer (Figure S27, Supporting information), which further corroborated the (15Z)-configuration of $\mathbf{3}$.

The remaining known diterpenoid analogues were identified as uncinatone (4) [16], teuvincenone E (5) [17], 12,16-epoxy-17(15 $\rightarrow 16), 18(4 \rightarrow 3)$-diabeo-abieta-3,5,8,12,15- pentaene-7,11,14-trione (6) [18], teuvincenone $F(7)$ [19], 12,16-epoxy-11,14-dihydroxy-6-methoxy-17(15 $\rightarrow 16)$-abeo-abieta5,8,11,13,15-pentaene-3,7-dione (8) [20], 17-hydroxymandarone B (9) [21], 12,16-epoxy-6,11,14,17- 
tetrahydroxy-17(15 $\rightarrow$ 16)-abeo-5,8,11,13,15-abietapentaen-7-one (10) [22], 6-methoxyvillosin $\mathrm{C}(\mathbf{1 1})$ [23], 15-dehydro-17-hydroxycyrtophyllone A (12) [19], sugiol (13) [24], on the basis of spectroscopic analyses and comparison with those reported in the literature.

All the isolates were evaluated for their inhibitory effect against $\alpha$-glucosidase in an in vitro bioassay model. As shown in Table 2, compounds 2, 4, 6 and 12 displayed much stronger inhibitory activity than the control drug acarbose, with $\mathrm{IC}_{50}$ values in the range of 17.0-25.7 $\mu \mathrm{M}$.

Table S3. $\alpha$-Glucosidase inhibitory activity of diterpenoids $\mathbf{1}-\mathbf{1 3}\left(\mathrm{IC}_{50}\right.$ in $\left.\mu \mathrm{M}\right)$

\begin{tabular}{cccc}
\hline Compopunds & IC $_{\mathbf{5 0}}$ & Compounds & IC $_{\mathbf{5 0}}$ \\
\hline $\mathbf{1}$ & $\mathrm{NT}$ & $\mathbf{8}$ & $\mathrm{NT}$ \\
$\mathbf{2}$ & $17.0 \pm 2.3$ & $\mathbf{9}$ & $\mathrm{NT}$ \\
$\mathbf{3}$ & $\mathrm{NT}$ & $\mathbf{1 0}$ & $\mathrm{NT}$ \\
$\mathbf{4}$ & $11.9 \pm 3.6$ & $\mathbf{1 1}$ & $\mathrm{NT}$ \\
$\mathbf{5}$ & $\mathrm{NT}$ & $\mathbf{1 2}$ & $19.0 \pm 1.6$ \\
$\mathbf{6}$ & $25.7 \pm 1.8$ & $\mathbf{1 3}$ & $\mathrm{NT}$ \\
$\mathbf{7}$ & $\mathrm{NT}$ & Acarbose & $236.0 \pm 14.0$ \\
\hline
\end{tabular}

\section{Acknowledgments}

We thank the Young Taishan Scholars Program [No. tsqn20161037], the Natural Science Foundation of Shandong Province [No. JQ201721] and Innovation Team Project of Jinan Science \& Technology Bureau [No. 2018GXRC003] for funding supports.

\section{Supporting Information}

Supporting information accompanies this paper on http://www.acgpubs.org/journal/records-ofnatural-products

\section{ORCID}

Dong-Xiang Wu: 0000-0003-2125-1792

Jin-Hai Yu: $\underline{0000-0002-9454-1750}$

Xiu-Qing Song: 0000-0001-5701-4145

Yu-Zhen Ma: 0000-0002-4736-3066

Peipei Shan: 0000-0002-0553-4728

Hua Zhang: 0000-0002-5959-6473

\section{References}

[1] Editorial Committee of Flora of China. (1982). Flora of China, Beijing. Scientific Press. $65(1), 176$.

[2] H. Yu and H.S. Yan (2018). A review of the medicinal applications and studies on 'Dai' medicine 'Binliang (Clerodendrum bungei)', Zhongguo Minzu Yiyao Zazhi (in Chinese) 24, 47-48.

[3] A.N. Yu (2004). Studies on the chemical constituents of the volatiles of Clerodendrum bungei, China J. Chin. Mater. Med. (in Chinese) 29, 157-159.

[4] L.M. Gao and X.M. Wei (2003). Studies on chemical constituents of Clerodendrum bungei, China J. Chin. Mater. Med. (in Chinese) 28, 1042-1044.

[5] J.L. Ruan and C.H. Fu (1997). Chemical constituents from the stems of Clerodendrum bungei, Zhongcaoyao (in Chinese) 28, 395-396.

[6] G.J. Zhang, L.M. Dai, B. Zhang, Y.L. Zhang and D. Liang (2017). Studies on chemical constituents of Clerodendrum bungei, China J. Chin. Mater. Med. (in Chinese) 42, 4788-4793.

[7] L. Sun, Z. Wang, G. Ding, Y. Bi, Z.P. Meng and W. Xiao (2014). Isolation and structure characterization of two new diterpenoids from Clerodendrum bungei, Phytochem. Lett. 7, 221-224.

[8] S.S. Liu, H.L. Zhu, S.W. Zang, X.H. Zhang and L.J. Xuan (2008). Abietane diterpenoids from Clerodendrum bungei, J. Nat. Prod. 71, 755-759. 
[9] S.K. Kim, S.B. Cho and H.I. Moon (2010). Anti-complement activity of isolated compounds from the roots of Clerodendrum bungei Steud, Phytother. Res. 24, 1720-1723.

[10] Q. Liu, H.J. Hu, P.F. Li, Y.B. Yang, L.H. Wu, G.X. Chou and Z.T. Wang (2014). Diterpenoids and phenylethanoid glycosides from the roots of Clerodendrum bungei and their inhibitory effects against angiotensin converting enzyme and $\alpha$-glucosidase, Phytochemistry 103, 196-202.

[11] X.L. Huang, D. Wu, J. Shu, L.Z. Fang and S.H. Zhang (2019). $\alpha$-Glucosidase inhibitory activity-guided identification of compounds from Clerodendrum bungei steud by HPLC-ESI-QTOF-MS/MS, Zhongguo Shuzi Yixue (in Chinese) 2, 41-49.

[12] J. Sun, J.H. Yu, J.S. Zang, X.Q. Song, J. Bao and H. Zhang (2019). Chromane enantiomers from the flower buds of Tussilago farfara L. and assignments of their absolute configurations, Chem. Biodivers. 16, e1800581.

[13] H.V. Oanh, P.X. Sinh, N.T. An, T.M. Hung and P.V. Kiem (2009). A new rearranged abietane diterpene and other constituents from Clerodendrum philipinum, Nat. Prod. Commun. 4, 323-325.

[14] M.F. Xu, L.Q. Shen, K.W. Wang and Q.Z. Du (2010). A new abietane diterpenoid from Clerodendrum kaichianum Hsu, J. Chem. Res. 12, 722-723.

[15] B.V. Le, T.M.N. Nguyen, Y.Y. Seo, H.K. Jang, T.V. Le, H.T.T. Phan, V.T. Nguyen, X.C. Nguyen, H.N. Nguyen, V.M. Chau, H. Inkyu and H. Young (2018). A new rearranged abietane diterpene from Clerodendrum inerme with antioxidant and cytotoxic activities, Nat. Prod. Res. 32, 2001-2007.

[16] A.C. Dorsaz, A. Marston, E.H. Stoeckli, J.D. Msonthi and K. Hostettmann (1985). Uncinatone, a new antifungal hydroquinone diterpenoid from Clerodendrum uncinatum Schinz, Helv. Chim. Acta. 68, 16051610 .

[17] B. Maurizio, C.T. Maria, S. Giuseppe, P. Franco and R. Benjiamin (1990). A rearranged abietane diterpenoid from the root of Teucrium fruticans, Phytochemistry 29, 2710-2712.

[18] J.S.C. Maria, B. Maurizio, C.T. Maria, P. Franco, S. Giuseppe and R. Benjamin (1992). Rearranged abietane diterpenoids from the root of two Teucrium species, Phytochemistry 31, 1697-1701.

[19] C.P.D. Maria, A.L.S. Mary, B.F. Raimundo and R.S. Edilberto (2003). ${ }^{1} \mathrm{H}$ and ${ }^{13} \mathrm{C}$ NMR assignments of abietane diterpenes from Aegiphila lhotzkyana, Magn. Reson. Chem. 41, 731-734.

[20] H.J. Hu, Y. Zhou, Z.Z. Han, Y.H. Shi, S.S. Zhang, Z.T. Wang and L. Yang (2018). Abietane diterpenoids from the roots of Clerodendrum trichotomum and their nitric oxide inhibitory activities, J. Nat. Prod. 81, 1508-1516.

[21] A. Fiorentino, B. Dabrosca, S. Pacifico, M. Scognamiglio, G. Dangelo and P. Monaco (2010). Abeoabietanes from Teucrium polium roots as protective factors against oxidative stress, Bioorg. Med. Chem. 18, 8530-8536.

[22] W.X. Wang, J. Xiong, Y. Tang, J.J. Zhu, M. Li, Y. Zhao, G.X. Yang, G. Xia and J.F. Hu (2013). Rearranged abietane diterpenoids from the roots of Clerodendrum trichotomum and their cytotoxicities against human tumor cells, Phytochemistry 89, 89-95.

[23] Q. Liu, H.J. Hu, P.F. Li, Y.B. Yang, L.H. Wu, G.X. Chou and Z.T. Wang (2014). Diterpenoids and phenylethanoid glycosides from the roots of Clerodendrum bungei and their inhibitory effects against angiotensin converting enzyme and $\alpha$-glucosidase, Phytochemistry 103, 196-202.

[24] Y.M. Weng, X. Yu, J. Li, Q.Z. Dong, F.S. Li, F. Cheng, Y. Zhang, C.P. Yao, Z.Y. Zou, W.H. Zhou, G.S. Tan and K.P. Xu (2018). Abietane diterpenoids from Lycopodium complanatum, Fitoterapia 128, 135141.

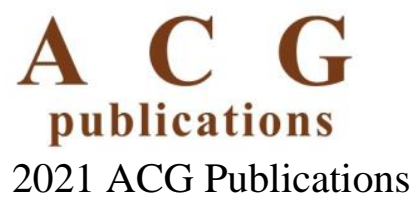

